\title{
Pharmacological Modification of Blood-Brain Barrier Permeability Following a Cold Lesion
}

\author{
Jennifer J. Raymond, David M. Robertson, Henry B. Dinsdale, and Sukriti Nag
}

\begin{abstract}
The effect of desipramine, imidazole, thioridazine and trifluoperazine on blood-brain barrier (BBB) permeability after a 24 hour cold lesion was studied in rats. Changes in BBB permeability were determined using a quantitative horseradish peroxidase (HRP) assay. The four drugs tested did not alter the quantity of HRP in the cortex of control animals, or in the contralateral cortex of test animals. However, imidazole, desipramine and trifluoperazine significantly reduced the HRP extravasation in and around the cold lesion. Several mechanisms for this effect are suggested; one possible mechanism common to all these drugs is the reduction of increased vesicular transport in cortical vessels adjacent to the cold lesions.
\end{abstract}

RÉSUMÉ: L'effet de la désipramine, de l'imidazole, de la thioridazine, et de la trifluopérazine sur la perméabilité de la barrière hémato-encéphalique (BHE) après une exposition au froid de 24 heures a été étudié chez le rat. Des changements dans la perméabilité de la BHE ont été calculés en employant un titrage quantitatif de la péroxidase de raifort (PR). Les quatre drogues essayées n'ont pas modifié la quantité du PR dans le cortex des animaux contrôles, ni dans le cortex contra-latéral des animaux expérimentaux. Cependant, l'imidazole, la désipramine, et le trifluopérazine ont réduit significativement l'extravasation du PR dans et autour de la lesion par le froid. Plusieurs mecanismes pour expliquer cet effet sont suggerés; un mecanisme possible qui est commun à toutes ces droques est la reduction du transport vesiculaire augmenté dans les vaisseau corticaux adjacent aux atteintes induites par le froid.

Can. J. Neurol. Sci. 1984; 11:447-451

Several animal models have been used to study changes in permeability of the blood brain barrier (BBB). Increased pinocytosis is a factor in such permeability changes in cortical vessels and has been demonstrated in association with acute hypertension (Hansson et al., 1975, 1980; Nag et al., 1977), seizures (Westergaard et al., 1978) and infusion of hyperosmolar solutions (Hansson et al., 1980). Cryogenic lesions also produce damage to the $\mathrm{BBB}$ with a characteristic central necrotic area in which the endothelial cells are diffusely permeable to tracers (Cancilla et al., 1979; Mitchell et al., 1979). Vessels in the adjacent cortex contain increased numbers of pinocytotic vesicles (Baker et al., 1971; Cancilla et al., 1979; Mitchell et al., 1979).

Three of the drugs tested in this study, thioridazine, trifluoperazine and desipramine are commonly used in the treatment of psychoses and depression; hence most previous research has focused on their behavioural and neurotransmitter effects. However, they are known to exert an effect on plasma membranes in culture (Connor et al., 1981; Horwitz et al., 1981; Josefsson et al., 1975). Imidazole, the fourth drug used in this study, reduces protein leakage through the blood-aqueous barrier in the eye (Bengstsson, 1977). Johansson (1981) found that pretreatment with these drugs reduced albumin extravasation during acute hypertension in rats and suggested that the drugs acted by reducing vesicular transport.

Pharmacological modification of abnormal BBB function is of great clinical relevance. Few drugs achieve this in humans, but one of note is dexamethasone (Faubel et al., 1976; Hoppe et al., 1981).

The cold lesion model results in increased vesicular transport in cortical vessels adjacent to the central necrotic core of the lesion. We used this model of injury to determine if these drugs could pharmacologically alter barrier function. This paper examines the effects of four drugs, imidazole, trifluoperazine, desipramine and thioridazine on the quantitative extravasation of HRP 24 hours after a cryogenic lesion.

\section{METHODS}

Female Wistar rats (Canadian Breeding Farms and Laboratories Ltd., La Prairie, Quebec) (180-220 g) were divided into two main groups: (1) test animals which received a cryogenic lesion in the right cortex and, (2) controls which had no operation. Test animals were anaesthetized with methyoxyflurane (Meto-

From the Departments of Pathology and Medicine, Queen's University and Kingston General Hospital, Kingston, Ontario

Received May 31, 1984. Accepted September 18, 1984

Reprint requests: Dr. Jennifer J. Raymond, Queen's University, Department of Pathology, Richardson Laboratory, Kingston, Ontario, Canada K7L 3N6 
fane, Pitman-Moore, Inc., Scarborough, Ontario), and a portion of skull $2 \mathrm{~mm}$ in diameter was removed in the right parietal area using a $2 \mathrm{~mm}$ bit on a dentist's drill. A cryogenic lesion was produced in the cortex by placing a $1.2 \mathrm{~mm}$ diameter copper probe, attached to a container of liquid $\mathrm{N}_{2}$, on the exposed dura for 30 seconds. The lesions were studied 24 hours later.

The tracer used in these experiments was HRP, a protein which is similar in size to albumin, having a molecular weight of 40,000 . The tracer was injected via the femoral vein and allowed to circulate for 5 minutes. Two methods were used to remove excess tracer from the cerebral circulation and the results were compared.

\section{Preparation of tissue for analysis}

Following brain removal, the surface diameter of the lesion was measured and a $50-60 \mathrm{mg}$ portion of cortex was excised. This measured approximately $5 \times 5 \times 2 \mathrm{~mm}$, and included the lesion at the centre. Care was taken to make a shallow cut to exclude white matter. A sample of cortex from the corresponding region of the contralateral hemisphere was taken in the same manner. Brain samples were homogenized in a Brinkman polytron to make a $10 \%$ homogenate in $0.9 \% \mathrm{NaCl}$ and $100 \mu \mathrm{l}$ of $1 \%$ Triton X-100 (Sigma) was added. Samples were kept at $4^{\circ} \mathrm{C}$ for 30 minutes before being centrifuged at $10,000 \mathrm{~g}$ for 10 minutes. Supernatants were assayed for HRP activity.

\section{Measurement of HRP}

HRP was measured by a modification of the method of Steinman and Cohn (1972). Fifty $\mu$ l of supernatant was added to $3 \mathrm{ml} 0.05$ $\mathrm{M}$ phosphate buffer ( $\mathrm{pH} 5.0)$ containing $60 \mu \mathrm{l}$ of $0.5 \%$ ( $\mathrm{v} / \mathrm{v} \mathrm{H}_{2} \mathrm{O}_{2}$ and $50 \mu \mathrm{l}$ of $1.0 \%(\mathrm{~W} / \mathrm{V})$-dianisidine (Sigma). The rate of development of a coloured product was measured at $460 \mathrm{~nm}$ on a Coleman Model 124 spectrophotometer and recorded on a Fisher Recordall series 5000 for 1-3 minutes. There was a small increase in absorbance of sample blanks not containing $\mathrm{H}_{2} \mathrm{O}_{2}$; this change in absorbance was subtracted from that of the samples. Results were expressed as change in optical density per $\mathrm{mg}$ protein in the homogenate where 1 unit of HRP activity equals increase of $1 \mathrm{OD}$ unit/min at $460 \mathrm{~nm}$ at $22^{\circ} \mathrm{C}$. Protein was determined by the method of Lowry et al. (1951). HRP activity in both the right (containing the lesion) and the left cortex were compared and expressed as a ratio of HRP activity in R cortex/ L cortex.

\section{Quantitation of tracer}

a) Perfusion method: Rats under methoxyfluorane anaesthesia were injected with $50 \mathrm{mg}$ HRP (Sigma type II) via the femoral vein and five minutes later perfused transcardially with $0.9 \% \mathrm{NaCl}$. Quantitation of remaining HRP activity was difficult due to a large variability in perfusion. There was also a marked asymmetry in the perfusion in which HRP levels in the right cortex were consistently lower than those in the left cortex. We therefore decided to study HRP activity in exsanguinated rats.

b) Exsanguination model: Twenty-four hours after the lesions were produced, $2 \mathrm{mg} \mathrm{HRP}$ in $1 \mathrm{ml} 0.9 \% \mathrm{NaCl}$ was injected over one minute via the femoral vein, and HRP was allowed to circulate for five minutes before the chest cavity was opened. The right atrium was incised and the animal was bled in a vertical position for two minutes. The brain was removed and tissue samples prepared as described above. Erythrocytes pos- sess a small amount of peroxidase activity. In this method the RBCs are not removed entirely, so endogenous peroxidase levels were examined in both test and control animals which did not receive HRP.

\section{Drug treatment}

The four drugs, desipramine ${ }^{*}$, trifluoperazine**, thioridazine ${ }^{* *}$ and imidazole used in the quantitative HRP studies were dissolved in $0.9 \% \mathrm{NaCl}$. Test and control animals received the same drug treatment. The injection schedule for all four drugs was identical and consisted of intraperitoneal injections one hour before, seven hours after, and twenty-two hours after the cryogenic lesion. Doses used in each injection were based on earlier studies (Johansson et al., 1981) Desipramine $\mathrm{HCl}, 5$ $\mathrm{mg} / \mathrm{kg}$; trifluoperazine $1 \mathrm{mg} / \mathrm{kg}$; thioridazine $5 \mathrm{mg} / \mathrm{kg}$ and imidazole $150 \mathrm{mg} / \mathrm{kg}$ in the first and third injection and $100 \mathrm{mg} / \mathrm{kg}$ imidazole in the second injection.

\section{Results}

The average diameter of the lesion produced was $3 \mathrm{~mm}$ and did not vary significantly in any of the groups studied (Table 1).

Endogenous peroxidase levels in cerebral cortex of exsanguinated rats were measured and the results are shown in Table 2. These animals received no drug treatment. The level of peroxidase in right and left cortex of controls and the left cortex (contralateral to lesion) of test animals were similar. However, the level in the damaged right cortex of test animals was increased by $70 \%$ due to increased numbers of RBCs in the necrotic core of the lesion.

The majority of experiments were performed on exsanguinated animals which were given $2 \mathrm{mg}$ HRP five minutes before sacrifice. This small amount of circulating HRP was chosen because high levels of circulating HRP cause hypotension (Diemann et al., 1976) and vascular leakage (Cotran and

\begin{tabular}{lc}
\hline Table 1: Mean size of lesion in right cortex of test animals \\
\hline \hline Experimental Group & Lesion dimensions $(\mathrm{mm})$ \\
\hline Untreated & $3.1 \pm 0.2^{*} \times 2.9 \pm 0.2(6)$ \\
Imidazole & $3.1 \pm 0.2 \times 2.9 \pm 0.2(7)$ \\
Desipramine & $3.1 \pm 0.2 \times 2.9 \pm 0.2(7)$ \\
Trifluoperazine & $3.2 \pm 0.3 \times 3.0 \pm 0.1(8)$ \\
Thioridazine & $3.3 \pm 0.3 \times 3.1 \pm 0.2(6)$ \\
\hline
\end{tabular}

Number of animals is given in brackets.

* Standard deviation.

Table 2: Endogenous levels of peroxidase in left and right cortex of untreated control and test animals (mean \pm SD in units per $\mathrm{mg}$ protein) Left Cortex Right Cortex R/L Cortex \# Animals

\begin{tabular}{lllll}
\hline Controls & $0.026 \pm .007$ & $0.027 \pm .008$ & $1.04+0.5$ & (5) \\
Test Animals & $0.025 \pm .007$ & $0.043 \pm .015$ & $1.72 \pm .33$ & (6) \\
\hline
\end{tabular}

(lesion in R. cortex)

* Desipramine $\mathrm{HCl}$ (Pertofane) was donated by Geigy Pharmaceuticals and ${ }^{* *}$ Thioridazine $\mathrm{HCl}$ and Trifluoperazine were the gift of Apotex Inc., Weston, Ontario, Canada. 


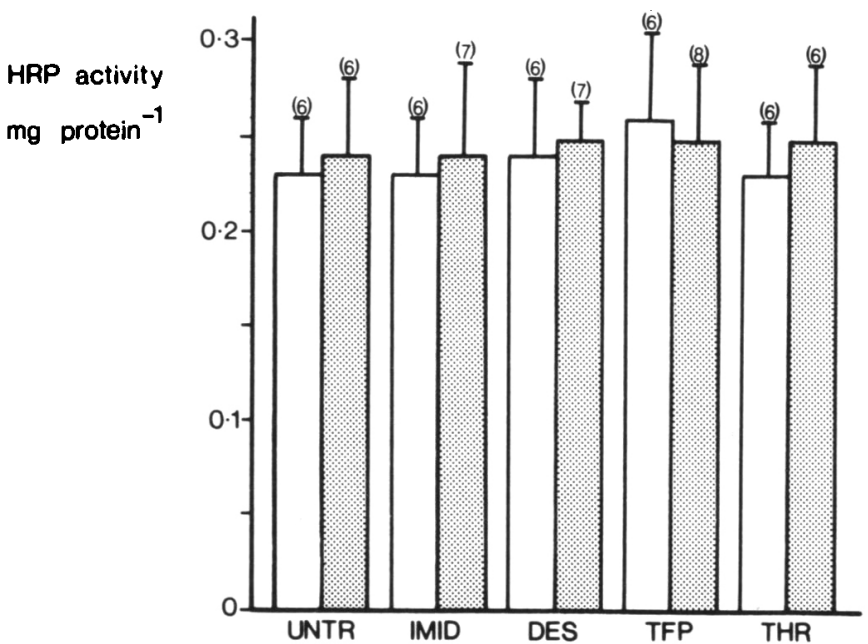

Figure 1-HRP levels in the left cortex of test and control animals. HRP activity was measured in $O D$ units per $\mathrm{mg}$ protein of homogenate. Test animals $\square$ received a cold lesion in the right cortex 24 hours earlier. Controls $\square$. Dosage and injection schedules for IMID (imidazole) DES (desipramine) TFP (trifluoperazine) and THR (thioridazine) are given in the text. Error bars denote $S D$ and the number of animals is given in brackets.

Karnovsky, 1967). The amount used provided adequate sensitivity for the biochemical assay and elevated the level in untreated control rats eightfold to 0.23 OD units/mg protein (Figure 1) from endogeneous levels of $0.026 \mathrm{OD}$ units $/ \mathrm{mg}$ protein (Table 2). This increase is sufficient to avoid interference by endogenous peroxidase in the quantitation of HRP.

In the drug studies, the doses of desipramine, thioridazine and trifluoperazine used were equivalent to high human therapeutic levels. Animals receiving thioridazine and trifluoperazine appeared lightly sedated; imidazole-treated rats were more sedated and desipramine-treated rats tended to be hyperactive.

The quantity of HRP in the left cortex of treated and untreated control rats did not differ significantly (Figure 2). This indicates that the drugs used in this study did not alter BBB permeability characteristics in control brains.

The levels of HRP in the contralateral (left) cortex of test animals were similar to control animals (Figure 1). This suggests that the permeability characteristics of the contralateral cortex are not affected by the lesion, and can be regarded as a built-in control.

Ratios of the level of HRP in Right/Left cortex in all control groups was not significantly different from 1.0. In test animals (Figure 2), the right cortex had more than twice the amount of HRP than the left $(R / L=2.090)$. The increase in HRP extravasation was reduced by more than $50 \%(\mathrm{R} / \mathrm{L}=1.409)$ after imidazole treatment and to a slightly lesser extent by desipra$\operatorname{mine}(\mathrm{R} / \mathrm{L}=1.594)$ and trifluoperazine $(\mathrm{R} / \mathrm{L}=1.662)$. Thioridazine treatment also reduced the degree of HRP extravasation but the value was not significant.

\section{Discussion}

The 24 hour cold lesion was chosen as a model of BBB breakdown for two main reasons. First, it is relatively simple to standardize the size of lesion produced and localize the damage to a specific area, unlike the hypertensive model, in which vessels become permeable in a more random fashion. Second,

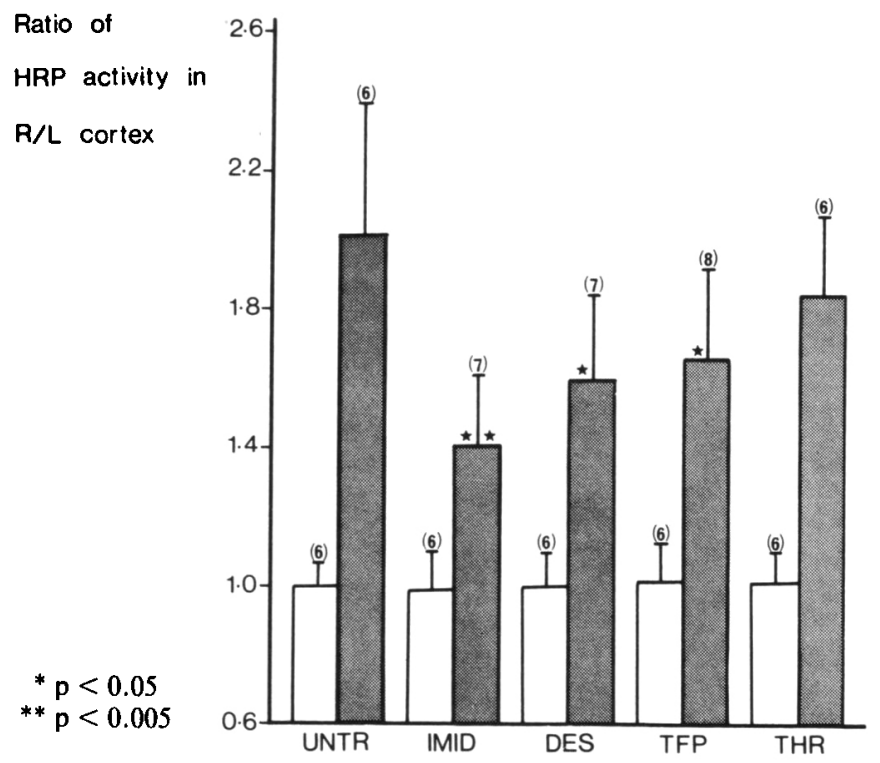

Figure $2-Q$ uantity of HRP in $R$ cortex/L cortex. Test animals received a lesion 24 hours earlier in the right cortex. The HRP activity (OD units per mg protein) in the left cortex of both test and control animals $\square$ was used as a reference to express increase in HRP activity in right correx. Dosage and injection schedules for IMID (imidazole) DES (desipramine) TFP (trifluoperazine) and THR (thioridazine) are given in the text. Error bars denote $S D$ and the number of animals is given in brackets.

the cortex contralateral to the lesion in test animals provides a built-in control.

Ultrastructural studies of one and three day old cold lesions demonstrated diffuse staining of cytoplasm in some endothelial cells in the necrotic zone, but the majority of HRP leakage in the adjacent area appeared to be due to increased vesicular transport (Cancilla et al., 1979; Mitchell et al., 1979).

Trifluoperazine reduces fusion of plasma cell membranes (Poste and Reeve, 1972), cell migration (Connor et al., 1981), phagocytosis (Horwitz et al., 1981) and pinocytosis (Josefsson and Hansson, 1975) by cells in culture. Such properties may be associated with the binding of trifluoperazine to calmodulin and the subsequent suppression of calmodulin-activated enzymes. Several of these calmodulin-regulated enzymes are present in plasma membranes and are involved with membrane transport such as adenylate cyclase (Seamon and Daly, 1982) and $\mathrm{Ca}++$ ATPase (Sobue et al., 1979).

Trifluoperazine reduces BBB breakdown in acute hypertension and Johansson (1981) suggested inhibition of vesicular transport as a possible mechanism. In our model, one way in which trifluoperazine may reduce HRP extravasation in and around the cold lesion is by suppressing pinocytosis and/or membrane transport.

Pappius and Wolfe (1983) recently demonstrated an increase in prostaglandin production in the area of a cold lesion. Phospholipase $A_{2}$ activity is activated in damaged cells and is an important enzyme in prostaglandin production (Flower and Blackwell, 1976). Moskowitz et al. (1983) found that calmodulin stimulates this activity and so it is possible trifluoperazine could exert an effect in our model by a reduction of prostaglandin production and the associated increase in vessel permeability (Kontos et al., 1980).

Other phenothiazines such as thioridazine have similar effects on cell membranes. For example, thioridazine is more effective 
in reducing pinocytosis by Amoeba Proteus than trifluoperazine. (Josefsson and Hansson 1985). Johansson (1981) found thioridazine reduced albumin extravasation during acute hypertension. In our study, this drug only reduced HRP leakage to a small extent. Thioridazine may act by a similar mechanism but there is a considerable difference between the two models, and it is likely that several other factors are also involved.

Desipramine, in contrast, acts by causing feedback inhibition of nor-adrenergic nerves by binding to presynaptic $\alpha$-receptors (Svensson and Usdin, 1978). It also suppresses the activation of adenylate cyclase by norepinephrine (Vetulani and Sulser, 1975) thus reducing the amount of cAMP in the tissue. Joo et al. (1975) and Westergaard (1975) have demonstrated that cAMP may be involved in the formation of pinocytotic vesicles in cerebral vessels, so it is plausible that treatment with desipramine could reduce HRP leakage by pinocytosis around the cold lesions.

Since Fauster et al. (1983) have shown that desipramine inhibits phospholipid degradation by lysosomes, desipramine could reduce membrane breakdown in the necrotic and adjacent area and so reduce HRP extravasation. Desipramine also reduces depression of glucose metabolism in the cortex surrounding a 24 hour cold lesion (Pappius, personal communication) and hence minimizes the damaging effect of the lesion and could in turn reduce permeability of control vessels in this area. In contrast, Preskhorn and co-workers (1980) found capillaries became more permeable to water immediately after treatment with tricyclic drugs, although, the doses used were greater than those used in both this study and that performed by Johansson (1981) in which desipramine reduced BBB breakdown.

Imidazole has an anti-histaminic action (Goto and Watnabe 1978; Morris and Dragstedt 1945; Puig-Parellada et al., 1973) and also activates phosphodiesterase which converts cAMP to 5'-AMP (Goodman, 1969; Morris and Dragstedt 1945). Zink and co-workers $(1973,1975)$ showed that imidazole inhibits the increase in intraocular pressure induced by prostaglandin $\mathrm{E}$ and Bengtsson (1977) also found it reduced the effect of $\alpha$-melanocytic stimulating hormone ( $\alpha-\mathrm{MSH})$ on the bloodaqueous barrier in the eye. Both groups speculate that the major mechanism of action of the compound is by lowering cAMP levels. Johansson (1981) found that pre-treatment with imidazole reduced albumin extravasation during acute hypertension, and suggested this finding supports the theory of Joo et al. (1975) and Westergaard (1975) that cAMP is involved in the regulation of pinocytosis in cerebral endothelium. The fact that imidazole significantly reduced HRP extravasation in the present study may also support this theory.

Additional regulators of adenylate cyclase activity in brain are $\mathrm{H}_{1}$ - and $\mathrm{H}_{2}$-histamine receptors (Palacios et al., 1978; Portaleone et al., 1978). Both types of receptor have been demonstrated in mammalian brain though only $\mathrm{H}_{2}$-receptor function has been clearly characterized (see review by Gross, 1982). Nevertheless, adenylate cyclase appears to be mediated mainly by $\mathrm{H}_{2}$ receptors (Palacios et al., 1978).

Histamine infusion increases the permeability of cerebral microvessels (Gross et al., 1982). This effect is mediated primarily through $\mathrm{H}_{2}$ receptors. Imidazole can act as an $\mathrm{H}_{2}$-receptor antagonist (Goto et al., 1978) and could exert its effect through $\mathrm{H}_{2}$-receptors in our model to reduce adenylate cyclase activity. Similarly, desipramine blocks $\mathrm{H}_{2}$-receptors in guinea pig hippocampus and reduces adenylate cyclase activity (Kanof and Greengard, 1978).

To conclude, we found that treatment with imidazole, desipramine or trifluorperazine reduced the amount of HRP extravasation in and around the area of a 24 hour cold lesion. Several mechanisms for this effect are suggested, and one common to all these drugs is the lowering of cAMP levels, which in turn may reduce the rate of pinocytosis in the area adjacent to the lesion.

\section{ACKNOWLEDGEMENT}

Supported by Medical Research Council of Canada, Grant \# 1647.

\section{REFERENCES}

Baker RN, Cancilla PA, Pollock PS and Frommes SP (1971) The movement of exogenous protein in experimental cerebral edema. An electron microscopic study of freeze injury. J. Neuropathol. Exp. Neurol., 30: 668-679.

Bengtsson, E (1977) Studies on the mechanism of the breakdown of the blood-aqueous barrier in the rabbit eye. Acta Ophthalmol. Suppl., 130: 1-33.

Cancilla PA, Frommes SP, Kahn LE and DeBault LE (1979) Regeneration of cerebral microvessels. A morphologic and histochemical study after local freeze-injury. Lab. Invest., 40: 74-82.

Connor CG, Brady RC and Brownstein BL (1981) Trifluoperazine inhibits spreading and migration of cells in culture. J. Cell Physiol., 108: 299-307.

Cotran RS and Karnovsky MJ (1967) Vascular leakage induced by horse-radish peroxidase in the rat. Proc. Soc. Exp. Biol. Med., 126: 557-561.

Diemann W, Taugner R and Fahimi HD (1976) Arterial hypotension induced by horseradish peroxidase in various rat strains. J. Histochem. Cytochem., 24: 1213-1217.

Faubel F, Reulen HJ, Muller D, and Schurmann K (1976) Double-blind study on the effects of steroids on severe closed head injury. Dynamics of brain oedema, edited by Pappius, H.M., Feindel, W., Springer Verlag, Berlin 337-343.

Fauster R, Honnegger $U$ and Weismann U (1983) Inhibition of phospholipid degradation and changes of the phospholipid-pattern by desipramine in cultured human fibroblasts. Biochem. Pharmacol., 32: $1737-1744$

Flower RJ and Blackwell GJ (1976) The importance of phospholipidase- $A_{2}$ in prostaglandin biosynthesis. Biochem. Pharmacol., 25: 285-291.

Goodman HM (1969) Metabolic effects of imidazole in adipose tissue. Biochim. Biophys. Acta, 176: 60-64.

Goto Y and Watanabe K (1978) Anti-secretory effect of imidazole and its derivatives in an isolated gastric mucosa preparation and an anesthetized young chicken preparation: comparison with a histamine $\mathrm{H}_{2}$-receptor antagonist. Jpn. J. Pharmacol., 28: 185-195.

Gross PM (1982) Cerebral Histamine: Indications for neuronal and vascular regulation. J. Cereb. Blood Flow Metab., 2: 3-23.

Gross PM, Teasdale GM, Graham DI, Angerson WJ and Harper MA (1982) Intra-arterial histamine increases blood-brain transport in rats. Am. J. Physiol., 243: H307-H317.

Hansson HA, Johansson BB and Blomstrand C (1975) Ultrastructural studies on cerebrovascular permeability in acute hypertension. Acta Neuropathol. (Berl.), 32: 187-198.

Hansson HA and Johansson BB (1980) Induction of pinocytosis in cerebral vessels by acute hypertension and by hyperosmolar solutions. J. Neurosci. Res., 5: 183-190.

Hoppe E, Christensen L and Christensen KN (1981) The clinical outcome of patients with severe head injuries, treated with high-dose dexamethasone, hyperventilation and barbiturates. Neurochirurgia, 24: 17-20.

Horwitz SB, Chia GH, Harracksingh C, Orlow S, Pifko-Hirst S, Schneck J, Sorbara L, Speaker M, Wilk EW and Rosen OM (1981) Trifluoperazine inhibits phagocytosis in a macrophage-like cultured cell line. J. Cell Biol., 91: 798-802.

Johansson BB (1981) Pharmacological modification of hypertensive blood-brain barrier opening. Acta Pharmacol. Toxicol., 48: 242-247. 
Joo FZ, Rakonczay Z and Wolleman M (1975) cAMP-mediated regulation of the permeability in the brain capillaries. Experientia (Basel), 31: $582-584$.

Josefsson JO, Johansson G and Hansson SE (1975) Inhibition of induced pinocytosis in Amoeba proteus by membrane stabilizing drugs. Acta Physiol. Scand., 95: 270-285.

Kanof PD and Greengard P (1978) Brain histamine receptors as targets for antidepressant drugs. Nature, 272 (5651): 329-333.

Kontos HA, Wei EP, Povlishock JT, Dietrich WD, Magiera CJ and Ellis EF (1980) Cerebral arteriolar damage by arachidonic acid and prostaglandin $\mathrm{G}_{2}$. Science, 209: 1242-1245.

Lowry OH, Rosebrough NJ, Farr AL and Randall RJ (1951) Protein measurement with the folin reagent. J. Biol. Chem., 193: 265-275.

Mitchell J, Weller RO and Evans H (1979) Re-establishment of the blood-brain barrier to peroxidase following cold injury to mouse cortex. Acta Neuropathol. (Berl.), 46: 45-49.

Morris HC and Dragstedt CA (1945) The antihistaminic effect of imidazol. Proc. Soc. Exp. Biol. Med., 59: 311.

Moskowitz N, Shapiro L, Schook W and Puszkin S (1983) Phospholipase $\mathrm{A}_{2}$ modulation by calmodulin, prostaglandins and cyclic nucleotides. Biochem. Biophys. Res. Comm., 115: 94-99.

Nag S, Robertson DM and Dinsdale HB (1977) Cerebral cortical changes in acute hypertension. An Ultrastructural Study. Lab. Invest., 36: 150-161.

Palacios JM, Garbarg M, Barbin G and Schwartz JC (1978) Pharmacological characterization of histamine receptors mediating the stimulation of cyclic AMP accumulation in slices from guinea-pig hippocampus. Mol. Pharmacol., 14: 971-982.

Pappius HM (1981) Local cerebral glucose utilization in thermally traumatized rat brain. Ann. Neurol., 9: 484-491.

Pappius HM and Wolfe LS (1983) Functional disturbances in brain following injury: Search for underlying mechanisms. Neurochem. Res., 8: 63-72.

Portaleone P, Pagnini G, Crispino A and Genazzani E (1978). Histaminesensitive adenylate cyclase in hypothalamus of rat brain: $\mathrm{H}_{1}$ and $\mathrm{H}_{2}$ receptors. J. Neurochem., 31: 1371-1374.
Poste $G$ and Reeve P (1972) Inhibition of virus-induced cell fusion by local anaesthetics and phenothiazine tranquillizers. J. Gen. Virol., 16: $21-28$.

Preskhorn SM, Hartman BK, Raichle ME and Clark HB (1980) The effect of dibenzazepines (tricyclic antidepressants) on cerebral capillary permeability in the rat in vivo. J. Pharmacol. Exp. Ther.. 213: 313-320.

Puig-Parellada P. Garcia-Gasulla G and Puig-Muset P (1973) Pharmacological properties of imidazole. 1. Analgesic and anti-inflammatory actions. Pharmacol., 10: 161-168.

Seaman KB and Daly JW (1982) Calmodulin stimulation of adenylate cyclase in rat brain membranes does not require GTP. Life Sci., 30: 1457-1464.

Sobue K, Ichida S, Yoshida H. Yamazaki R and Kakiuchi S (1979) Occurrence of a Ca ${ }^{2+}$ and modulator protein-activatable ATPase in the synaptic plasma membranes of brain. F.E.B.S. Lett., 99: 199-202.

Steinman RM and Cohn ZA (1972) The interaction of soluble horseradish peroxidase with mouse peritoneal macrophages in vitro. J. Cell Biol., 55: 186-204.

Svensson TH and Usdin T (1978) Feedback inhibition of brain noradrenaline neurons by tricyclic anti-depressants: $\alpha$-receptor mediation. Science, 202: 1089-1091.

Vetulani J and Sulser F (1975) Action of various anti-depressant treatments reduces reactivity of noradrenergic cyclic AMP-generating system in limbic forebrain. Nature. 257 (5526): 495-496.

Westergaard $E$ (1975) The effect of serotonin, norepinephrine and cyclic AMP on the blood-brain barrier. J. Ultrastruct. Res., 50: 383.

Westergaard E, Hertz MM and Bolwig TG (1978) Increased horseradish peroxidase across cerebral vessels, evoked by electrically induced seizures in the rat. Acta Neuropathol. (Berl.), 41: 73-80.

Zink HA, Podos SM and Becker B ( 1973) Inhibition by imidazole of the increase in intraocular pressure induced by topical prostaglandin $\mathrm{E}$. Nature (New Biol.), 245: 21-22.

Zink HA, Podos SM and Becker B (1975) Modification by imidazoles of ocular inflammatory and pressure responses. Invest. Ophthalmol., 14: $280-285$ 